nghiệp bác sĩ chuyên khoa II Đại học Y Hà Nội.

4. Nguyễn Văn Đồng (2017), "Nghiên cứu kết quả cắt tư cung do u xơ tử cung bằng phấu thuât nội soi tại Bệnh viện Phụ sản Thanh Hóa", Luận văn tốt nghiêp thac sỹ y hoc, trường đai hoc y Hà Nối.

5. Nguyễn Bá Mỹ Nhí, (2001), "Áp dưng cắt tử cung qua nội soi tại Bệnh viện Phụ - Sản Từ Dũ", Tap chí Phu - Sản số 2. p. 29 - 32.

6. Nguyễn Văn Giáp, (2006), "Nghiên cứu ứng dụng kỹ thuật cắt tư cung hoàn toàn tại bệnh viện
Phụ Sản trung ương tháng 12/2004 -6/2006", Luân văn tốt nghiệp bác sĩ chuyên khoa II Đại học Y Hà Nội.

7. Cao Thị Thùy Anh (2011), "Nghiến cứu các phương pháp phấu thuật u xơ tử cung tại bệnh viện phụ sản trung ương năm 2010", Luận văn tốt nghiệp bác sĩ chuyên khoa II Đại học Y Hà Nội.

8. Trinhh Xuân Hưởng (2015), "Nghiên cửu về phâu thuật điều trị u xơ tử cung tại bệnh viện phụ sản Hà nội năm 2014", Luận văn tốt nghiệp bác sĩ chuyên khoa II Đại học Y Hà Nội.

\title{
KHẢO SÁT HIỆU QUẢ CỦA PHẪU THUÂT NộI SOI MŨI XOANG KHÔNG ĐẶT BẤC MŨI
}

\section{TÓM TẮT}

Muc tiêu: Đánh giá hiệu quả của phẫu thuật nôi soi mũ̃i xoang (PTNSMX) không đặt bấc mũi ở bệnh nhân viêm xoang man tính có chỉ định phẩu thuật. Phương pháp nghiên cứu: mô tả cắt ngang hàng loat ca. Từ tháng 1/ 2018 đến $1 / 2021$ chúng tôi thực hiện PTNSMX cho 210 trường hợp tại khoa Tai Mũi Họng - Bệnh viện Chơ Rẫy. Kết quả: qua 210 trường hợp PTNSMX loại I đến loại IV chiếm 86,2\% kèm với chỉnh hình vách ngăn 16,7\%, chỉnh hình cuốn mũi dưới 10\% không đặt bấc mũi. Các triệu chứng nghet mũi, đau đầu, đau họng, đau mặt/ đau trong mũi cải thiên nhiều sau mổ. Cảm giác đau và thoải mái sau phẩu thuật dễ chịu cải thiện sớm. Kết luận: việc không đặt bấc mữi sau PTNSMX giúp mang lại hiệu quả, an toàn và thoải mái cho bệnh nhân, giúp cải thiện triệu chứng sớm và rút ngắn thời gian nắm viện chò bênh nhân.

Từ khóa: phẫu thuật nội soi mũi xoang không đặt bấc mũi.

\section{SUMMARY}

TO SURVEY EFFECT OF ENDOSCOPIC SINUS SURGERY WITHOUT USING NASAL

\section{PACKING}

Objectives: To evaluate effect of the endoscopic sinus surgery (ESS) without using nasal backing at Otolaryngology Department - Cho Ray Hospital from Jan, 2018 to 2021. Methods: Crossectional study without control group. There arc 210 patients underwent endoscopic sinus surgery at Otolaryngology Department - Cho Ray Hospital. Results: We performed 210 patients with endoscopic sinus surgery which is classificated from type I until type IV $(86,2 \%)$ and none using nasal packing. There arc 16,7\% septoplasty and 10\% inferior turbinoplasty. Almost symptoms of patients improved clearly such as nasal

*Bênh viện Chợ Rẫy

Chịu trách nhiệm chính: Ngô Văn Công

Email: congtmh@gmail.com

Ngày nhân bài: 13.5.2021

Ngày phản biên khoa họ: 5.7 .2021

Ngày duyệt bài: 16.7.2021
Ngô Văn Công*

obstruction, headache, sorethroat... Patients felt more comfortable after ESS without nasal packing. Conclusions: ESS without using nasal packing help more efficiency and safer. The patients felt more comfortable and improved almost symptoms after ESS. The hospitation is shorter.

Keywords: Functional endoscopic sinus surgery without nasal backing.

\section{I. ĐĂT VẤN ĐỀ}

Viêm mũi xoang mạn tính là một bệnh phổ biến nhất trong bệnh lý Tai Mũi Họng. Ở Mỹ, khoảng $16 \%$ dân số bị mắc bệnh, trong khi ở Hàn Quốc là 6,95\% dân số [1]. Triệu chứng viêm mũi xoang mạn tính gồm nhiều triệu chứng như: nghẹt mũi, chảy mũi, đau vùng mặt, rối loạn khứu giác, sốt,... Những triệu chứng này gây ảnh hưởng tiêu cực đến chất lượng cuộc sống của bênh nhân. PTNSMX nhằm loại bỏ bệnh tích cũng như tái lập lại lưu thông trong mũi xoang. Chăm sóc hậu phấu thích hợp cũng là một trong những điều kiện giúp cải thiện kết quả phẫu thuật và giảm khó chịu của bệnh nhân.

Sau phẫu thuật thì việc đặt bấc mũi (nhét mèche mũi) thường được thực hiện nhằm kiểm soát chảy máu hậu phấu, ngưua dính cuốn giữa [5]. Tuy nhiên, việc đặt bấc mũi cũng gây ra những khó chịu cho bệnh nhân như đau, nghẹt mũi, thở miệng, khô miệng, chảy nước mắt, nhiếm trùng... đồng thời cũng gây tổn thương niêm mạc hay chảy máu khi lấy ra. Theo xu hướng y học hiện đại, vừa điều trị tốt bệnh lý vừa quan tâm đến chất lượng cuộc sống của bệnh nhân sau PTNSMX, chúng tổi tiến hành nghiên cứu "khảo sát hiệu quả của PTNSMX không đặt bấc mũi".

II. ĐỐl TƯỢNG VÀ PHƯƠNG PHÁP NGHIÊN CỨU

2.1. Đối tượng nghiên cứu: Bệnh nhân được chẩn đoán bệnh lý mũi xoang và được điều 
trị tại PTNSMX tại khoa Tai Mũi Họng - Bệnh viện Chợ Rẫy từ tháng 12/2018 đến tháng 2/2020.

\subsection{Tiêu chuẩn chon mẫu:}

+ Được chẩn đoán bệnh lý viêm mũi xoang man và có chỉ đinh PTNSMX.

+ Theo phân loại hội mũi học Nhật Bản (2013) [4] về phẫu thuật nội soi xoang bao gồm 5 loai (loai I: mơ phức hợp khe giữa, với mở mỏm móc và mở rông lổ thông tin tư nhiên; loại II: mở các xoang đơn thuân với nắn chỉnh trong lòng xoang; loại III: thủ thuật cắt polyp; loại IV: mở rộng các xoang cạnh mũi; loại V: phẫu thuật mở rộng vượt qua các xoang).

+ Bệnh nhân đồng ý tham gia nghiên cứu.

2.3. Tiêu chuẩn loại trừ:

+ U mũi xoang

+ Những bệnh nhân sau phẫu thuật mũi không cầm được máu.

+ Bệnh lý nội khoa không thể phẫu thuật được.

+ Bệnh nhân không đồng ý tham gia nghiên cứu.

2.4. Phương pháp nghiên cứu: mô tả cắt ngang có can thiệp lâm sàng không đối chứng. Có 210 trường hợp nghiên cứu.

- Xư liệu số liệu bằng phân mềm SPSS 20.0

Bảng 1: Triệu chứng cơ năng

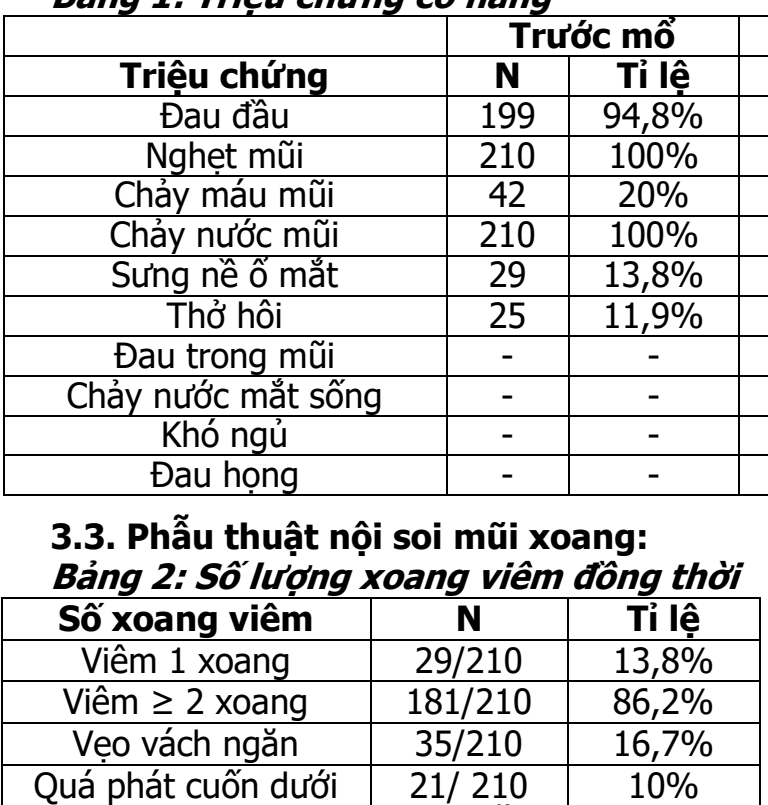

\section{Bảng 3: Phương pháp phấu thuật}

\begin{tabular}{|c|c|c|}
\hline Triệu chứng & $\mathbf{N}$ & Tỉ lệ \\
\hline Mở khe dưới & 60 & $28,6 \%$ \\
\hline Mở khe giữa & 210 & $100 \%$ \\
\hline Mở xoang bướm & 40 & $19 \%$ \\
\hline Chình hình vách ngăn & 35 & $16,7 \%$ \\
\hline Chình hình cuốn dưới & 21 & $10 \%$ \\
\hline Nạo sàng trước sau & 190 & $90,5 \%$ \\
\hline
\end{tabular}

\subsection{Tiến hành nghiên cứu:}

+ Bệnh nhân được chẩn đoán bệnh viêm mũi xoang và có chỉ định PTNSMX.

+ Ghi nhân thồng tin, các biến số.

+ Tiến hành PTNSMX

+ Sau PTNSM cầm máu kỹ bằng bipolar.

+ Chăm sóc mũi xoang sau phẫu thuật.

+ Sau phẫu thuật theo dõi biến chứng sau phẫu thuật, xuất viện khi đủ điều kiện, theo dõi diễn tiến bệnh bằng triệu chứng chính và nội soi mũi tại thời điểm trước mổ, trước khi xuất viện, 2 tuân, 1 tháng sau mổ.

\section{KẾT QUẢ NGHIÊN CỨU}

Qua 210 trường hợp PTNSMX được thực hiện trong thời gian nghiên cứu, chúng tôi ghi nhận kết quả như sau:

3.1. Đắc điểm chung: - Tuổi: từ 25 - 69 tuổi, tuổi trung bình $46.7 \pm 10.5$.

- Giới: nam/nữ = 1: 2 (70 nam, 140 nữ)

- Bệnh nhân bị đái tháo đường type 2: 35/210 (16,7\%).

- Viêm xoang biến chứng mắt 29/210 (13,8\%).

\subsection{Triệu chứng lâm sàng:}


29, tuổi lớn nhất là 64 . Nữ chiếm 66,7\%. Bệnh lý nội khoa đi kèm thường gặp nhiều nhất là đái tháo đường type 2. Trong đó, có 29/210 trường hợp $(13,8 \%)$ viêm xoang mạn tính có biến chứng mắt.

4.2. Triệu chứng lâm sàng: Triệu chứng lâm sàng của bệnh lý mũi xoang thì cũng tương tự các nghiên cứu. Các triệu chứng chính thường gặp như đau đầu/ nặng mặt, nghẹt mũi, chảy nước mũi, ...Trong nghiên cứu của chúng tôi, tất cả các bệnh nhân sau phẫu thuật đều không xuất hiện các biến chứng như: viêm ứ mủ, nhiễm trùng hốc mũi sau phẫu thuật,... So với nghiên cứu tác giả Huỳnh Ngọc Thành, với việc cầm máu bằng mèche mũi thì chảy máu chiếm $29.5 \%$ [2], với tác giả Phạm Mộng Hoàng thì chảy máu chiếm $8.5 \%$ [3].

Sau phẫu thuật các triệu chứng được cải thiện rõ rệt. Trong đó, việc không đặc bấc mũi sau PTNSMX giúp cho quá trình hậu phẫu của bệnh nhân sau phẫu thuật tốt hởn, các triệu chứng cải thiện sớm và bệnh nhân thoải mái hơn, đặc biệt các triệu chứng đau từ $52,4 \%$ giảm $9,5 \%$, chảy máu mũi từ $92,4 \%$ giảm $1,4 \%$, chảy nước mắt sống và cảm giác khó chịu sau mổ cải thiện nhiều. Các bệnh nhân sau PTNSMX từ ngày hậu phậu thứ 1 có thể thở bằng mũi, giảm hẳn các triệu chứng đau họng, chảy nước mắt sống, đau mũi/ mặt,... và bệnh nhân thoải mái hơn so với ghi nhận các bệnh nhân sau PTNSM đặt bấc mũi sau mổ và có thể xuất viện sớm ở ngày hậu phẫu thứ 2 chiếm $86,2 \%$, các bệnh nhân đặt merocel sau PTNSMX các triệu chứng thường cải thiện sau khi rút bấc mũi (sau 48h sau phẫu thuật), thường kèm chảy máu khí rút bấc mũi và xuất viện muộn hơn.

So với tác giả Huỳnh Ngọc Thành thì thời gian cải thiện triệu chứng phải 2 tuần sau mổ [2]. Điều này là do tác giả sử dụng bấc mũi để cầm máu và chỉ định rút sau 48 h, sau đó phải rửa mũi để loại bỏ các dịch tiết hay máu cũ trong mũi. Như vậy, không đặc bấc mũi sau PTNSMX giúp cải thiện triệu chứng lâm sàng cho bệnh nhân sớm hởn.

Một nghiên cứu của Xu và cộng sự [7] cho thấy nhóm không đặt bấc mũi cảm thấy thoải mái hơn và không bị chảy máu kèm với đau khi rút bấc mũi hơn so với nhóm đặt bấc mũi và đạt kết quả tốt hơn.

Việc sử dụng bấc mũi để cầm máu sau PTNSMX là hết sức phổ biến. Tuy nhiên, rút bấc mũi là điều hết sức khó chịu cho bệnh nhân trong suốt thời gian phẫu thuật. Ngoài ra việc sử dụng không thích hợp bấc mũi cũng làm tổn thương niêm mạc mũi cũng như làm cản trở quá trình lành niêm mạc sau phẫu thuật [6].

4.3. Phẫu thuật nội soi mũi xoang và kết quả sau PTNSMX: Đa số bệnh nhân (> 90\%) trong nghiên cứu chúng tôi đều xuất viện sau phẫu thuật 2 ngày sau khi theo dõi không xuất hiện bất kì biến chứng nào. Điều này cho thấy trong nghiên cứu chúng tôi bệnh nhân được rút ngắn thời gian nằm viện, bệnh nhân quay trở lại sinh hoạt bình thường với chất lượng sống tốt hơn. Chỉ có các trường hợp viêm xoang biến chứng mắt $13,8 \%$, bệnh nhân phải nằm viện 7 ngày để điều trị cũng như theo dõi biến chứng mắt. So với tác giả Huỳnh Ngọc Thành thì thời gian nằm viện trung bình là 7 ngày [2]. Điều này có thể giải thích do các bệnh nhân chúng tôi không cần phải ở lại nằm viện để rút bấc mũi, cũng như không có các triệu chứng khó chịu trong hậu phẫu. Như vậy, thời gian nằm viện sau PTNSMX đã được rút ngắn hơn, làm thuận tiện cho bệnh nhân trong việc điều trị và giảm chi phí đáng kể trong quá trình điều trị bệnh lý mũi xoang. Hầu hết các trường hợp phẫu thuật nội soi mũi xoang từ loại I đến loại IV chiếm $86,2 \%$, còn lại là phẫu thuật nội soi mũi xoang loại $\mathrm{V}$ chiếm 13,8\%.

Nghiên cứu của Xu [7] thì thường áp dụng không đặt bấc mũi cho các PTNSMX loại I và II không có bệnh toàn thân và tình trạng kính tế giới hạn. Điều này cũng phù hết với kết quả nghiên cứu của chúng tôi, tuy nhiên ở trong nghiên cứu chúng tôi gần như áp dụng không đặt bấc mũi cho các PTNSMX từ loại I đến loại IV là chiếm hầu hết các trường hợp với không có các bệnh lý về đông cầm máu.

Bên cạnh PTNSMX chúng tôi còn tiến hành phẫu thuật chỉnh hình vách ngăn qua nội soi $(16,7 \%)$ và sau đó khâu niêm mạc vách ngăn và rạch 1 phần niêm mạc vách ngăn phía sau để tránh tụ máu vách ngăn sau phẫu thuật. Cùng với chỉnh hình cuốn mũi dưới 10\%.

\section{KẾT LUÂ̂N}

Qua nghiên cứu chúng ta thấy rằng việc không đặt bấc mũi sau PTNSMX giúp mang lại hiệu quả và có tính an toàn cao cho bệnh nhân, giúp cải thiện triệu chứng sớm và rút ngắn thời gian nằm viện cho bệnh nhân.

\section{TÀI LIÊU THAM KHẢO}

1. Benninger MS, Ferguson BJ, Hadley JA, Hamilos DL, Jacobs M, Kennedy DW, et al. Adult chronic rhinosinusitis: definitions, diagnosis, epidemiology, and pathophysiology. Otolaryngol Head Neck Surg. 2003 Sep;129(3 Suppl):S1-32.

2. Huỳnh Ngọc Thành (2010), "Bước đâu ứng dụng nội soi điều trị các bệnh lý mũi xoang tại 
bệnh viện II Lâm Đồng"

3. Phan Mông Hoàng, Nghiêm Đức Thuân (2010), "Nghiên cứu các biến chứng và di chứng trong phẫu thuật nội soi chức năng mũi xoang tại bênh viện Củ Chi - TP.HCM", Y học thực hành, 728 (7), tr.75-77.

4. Kengo Kanai et al. Evaluation of a new and simple classification for endoscopic sinus surgery. Allergy Rhinol (Providence). 2017 Oct; 8(3): e118-e125.

5. Valentine $R$, Wormald $P J$, Sindwani $R$ Advances in absorbable biomaterials and nasal packing. Otolaryngol Clin North Am. 2009 Oct;42(5):813-28.

6. Yan M, Zheng D, Li Y, Zheng Q, Chen J, Yang B. Biodegradable nasal packings for endoscopic sinonasal surgery: a systematic review and metaanalysis. PLoS One. 2014 9(12):e115458.

7. $\mathbf{X u} \mathbf{W} 1, \mathbf{X u ~ G}, \mathbf{L i} B$, Li Y. [The application of no nasal packing after functional endoscopic sinus surgery in type I and type II chronic sinusitis]. Lin Chung Er Bi Yan Hou Tou Jing Wai Ke Za Zhi. 2012;26(24):1123-6.

\section{TỔNG HỢP TÁC DỤNG NGOÀI TRÁNH THAI CỦA CÁC BIỆN PHÁP TRÁNH THAI}

\section{TÓM TẮT}

Ngoài dụng cụ tử cung, các biện pháp tránh thai nội tiết đang ngày càng trở nên phổ biến không chỉ bởi hiệu quả tránh thai cao mà còn nhờ các tác dụng có lợi ngoài tránh thai. Do cơ chế hoạt động cũng như cách phân phối thuốc, các biên pháp tránh thai có hiệu quả trong điều trị một số vấn đề phụ khoa như đau bụng kinh (đăc biệt do lạc nội mạc tử cung) và cường kinh, giúp nâng cao chất lượng cuộc sống của người phụ nữ. Thuốc tránh thai cũ̃ng giúp cải thiện các bệnh lý nội khoa liên quan đến chu kỳ kinh nguyệt (đau đâu, hội chứng tiền kinh nguyết, mụn trứng cá). Các nghiên cứu cũng cho thấy tác dụng bảo vệ của thuốc tránh thai trong han chế nguy cơ một số loai ung thư đặc biệt là ung thư buồng trứng và ung thư niêm mạc tử cung. $Y$ văn cũng đề câp đến sự giảm nguy cơ ung thư niêm mạc tử cung và ung thư cổ tử cung của DCTC chứa đồng với độ tin cậy cao.

Tư khóa: Tránh thai nội tiết, dụng cụ tử cung (DCTC), tác dụng ngoài tránh thai, đau bụng kinh, ung thur.

\section{SUMMARY \\ NON-CONTRACEPTIVE EFFECTS OF CONTRACEPTION}

Besides IUD, the hormonal contraceptive methods become more and more popular because of not only high birth control effect but also non-contraceptive benefits. Due to their mechanism of action as well as delivery system, the contraceptions are successful in management of some gynecological conditions such as dysmenorrhea (especially owing to endometriosis) and menorrhagia, help to raise the standard of the women's living quality. Hormonal contraceptions also help to improve general medical conditions related to

${ }^{1}$ Bệnh viện Phụ Sản Trung Uơng

Chịu trách nhiệm chính: Nguyễn Ngọc Phương

Email: pika.hmu@gmail.com

Ngày nhận bài: 12.5.2021

Ngày phản biên khoa hoc: 2.7.2021

Ngày duyệt bài: 16.7.2021
Nguyễn Ngọc Phương1, Hà Duy Tiến ${ }^{1}$, Bùi Lê Khánh Chi ${ }^{1}$, Phùng Thị Phương Thúy ${ }^{1}$

menstrual cycles (migraines, premenstrual syndrome, acne). A reduction in ricks of some kinds of cancer, particularly ovarian and endometrial cancer is documented. Copper IUD use is associated with a decrease in cervix and endometrial cancer risk.

Keywords: hormonal contraception, Intrauterine device (IUD), non-contraceptive effect, dysmenorrhea, cancer.

\section{GIỚI THIẸU}

Các biện pháp tránh thai nội tiết và DCTC được sử dụng ngày càng rộng rãi đặc biệt là thuốc tránh thai chứa progestin tác dụng kéo dài (thuốc tiêm, que cấy, DCTC nội tiết) vì tính thuận tiện và hiệu quả tránh thai cao. Ngoài tác dụng chính là tránh thai, các biện pháp này có thể có các tác dụng phụ lên một số bệnh lý khác với vai trò dự phòng hoặc điều trị. Trong một số trường hợp, những hiệu quả đó trở thành tác dụng chính mà thuốc được sử dụng. Mục đích của bài viết này nhằm xem xét tổng quan về các các dụng ngoài tránh thai của các biện pháp tránh thai phổ biến hiện nay.

\section{CÁC THUỐC TRÁNH THAI NộI TIẾT VÀ DỤNG CỤ TỬ CUNG}

Các biên pháp tránh thai chứa nôi tiết và dụng cụ tử cung có nhiều loại chễ phẩm khác nhau (bảng 1), với các dạng trình bày, cách sử dụng và tác dụng khác nhau.

Bảng 1: Các biện pháp tránh thai nội tiêt và dụng cụ tứ cung

\begin{tabular}{|c|c|c|}
\hline \multicolumn{2}{|c|}{$\begin{array}{c}\text { Biện pháp tránh } \\
\text { thai }\end{array}$} & Chế phẩm \\
\hline \multirow{3}{*}{$\begin{array}{c}\text { Thuốc } \\
\text { tránh } \\
\text { thai } \\
\text { nội }\end{array}$} & \multirow{3}{*}{$\begin{array}{l}\text { Thuốc } \\
\text { tránh thai } \\
\text { kết hợp }\end{array}$} & $\begin{array}{l}\text { Viên uống tránh thai (1pha, } \\
\text { nhiều pha, uống liên tục) }\end{array}$ \\
\hline & & Miếng dán tránh thai \\
\hline & & Vòng đặt âm đạo \\
\hline
\end{tabular}

